\title{
Operating Room Management after 2008 Economic Crisis in Italy: A Literary Review
}

\author{
Andrea Rochira ${ }^{1}$, Andrea Ubiali ${ }^{1}$, Matteo Buccioli ${ }^{2}$, and Peter Perger ${ }^{3}$ \\ ${ }^{1}$ School of Hygiene and Preventive Medicine, San Giacomo 12 street, University of Bologna, Italy \\ ${ }^{2}$ IRCCS Rizzoli Orthopaedic Institute, Pupilli 1 street, Bologna, Italy \\ ${ }^{3} \mathrm{UMIT}$, Health and life science University, Austria
}

\section{Abstract}

The 2008 financial crisis has changed administration methods of various activities and productive services, including health services. In fact in Italy it was necessary a deep reorganization of the healthcare system due to a strong reduction in the funds allocated to the health sector. Consequently the management of the hospital operative theaters like operating rooms (OR) has become a priority aspect in the health administration. In this context we performed a literary review about experiences or projects of operating room management (ORM) carried out in Italy between 2007

Corresponding Author:

Andrea Rochira

rochiraandrea@gmail.com

Received: 17 November 2019

Accepted: 6 January 2019

Published: 12 January 2020

Publishing services provided by

Knowledge E

(c) Andrea Rochira et al. This article is distributed under the terms of the Creative Commons

Attribution License, which

permits unrestricted use and

redistribution provided that the

original author and source are credited.

Selection and Peer-review under the responsibility of the EBEEC Conference Committee.

\section{G OPEN ACCESS} and nowadays. We searched Medline database and we found 12 articles meeting the inclusion criteria. Only one paper was submitted in 2007 , the remain were drafted in the following years. The italian regions represented are mostly of the north center area. The topics discussed are heterogeneous: ORM reorganizations in clinical hospitals, simulations of models aimed to resolve OR slots assignment, surgical waiting lists management, OR process analysis and ORM literary review. Overall the results show that interest and competence for the ORM are quickly increasing in Italy. In fact, because OR are the most expansive and the most productive areas of every hospitals, it's of paramount relief to implement strategies in order to optimize OR quality and minimize the non-productive and unnecessary costs, especially in the current period of austerity measures and continuous cuts to public funds.

Keywords: hospitals, management, crisis, resources, surgery, healthcare, ORM

\section{Introduction}

The recent financial crisis occurred in 2008 had a strong impact on world economy, although not all countries were affected at the same way[1]. In Europe especially countries like Portugal, Spain, Italy, Ireland and Greece suffered the crisis[2].These nations had in common a high public debt and a low gross domestic product growth index. For these reasons their governments had to operate several cuts to public funds in order to reduce deficits and to restore balance. These austerity measures involved also the healthcare sector with serious consequences [3, 4].Therefore hospital managers 
had to find new strategies for healthcare administration aimed to reduce wastes and improve productivity, maintaining high quality standards of care.

In particular the new management models were mostly applied to critical areas of the hospitals like emergency and operating rooms (OR). In fact Operating Room Blocks (ORB) represent centerpiece in every hospital, since they monopolize the greatest part of their financial resources [5, 6]. Operating Room Management (ORM) aims to improve the utilization of surgical spaces and times, to reduce postponements or delays in surgical interventions, and, more in general, to preserve quality of care and patient safety [7-9].

ORM is playing an increasingly important role within hospital administrations, especially in the light of the recent global economic crisis, which had an important impact on healthcare systems all over the world in considerably downsizing healthcare spending. Italy, as cited above, has been highly hit by financial crisis which induced several negative consequences on the public resources.

The Italian National Health Service resulted to be deeply affected by this context [10], being subject to restrictive policies of cost containment, controls on regional spending and restrictions of personnel turnover. Strict regulations of shifts and schedules of healthcare professionals contributed to increase the rigidity of productive assets and processes [11].Moreover Italy issued, in recent years, both at national and regional level, institutional guidelines to manage in a proper and timely manner the provision of healthcare services, in order to reduce waiting times for users [12].This aspect has come to affect healthcare management in terms of planning and organization, with an important effect especially on surgical activities. Several studies are present in the literature about ORM $[13,14]$, especially from USA.

Few articles have been published in Italy and no study related to the italian area has been released. Since this statement, we conducted a review of the scientific literature focused on papers about ORM describing the state of the art of the italian context. The aim of this study is to describe the development and application of ORM in Italy, especially in relation to 2008 financial crisis. Thus our effort is to provide a useful overview on ORM literature for national and international practitioners and researchers.

\section{Body of Paper}

\subsection{Methods}

We browsed the scientific literature with focus on papers about ORM in Italy published in a time period between January 01, 2007 and December 31, 2018. We searched in 
Medline database using the following keywords combination: "operating room AND (planning OR management OR scheduling)".

In addiction we also performed hand-search and snowball-search in order to increase the sensitivity of our search. Inclusion criteria were the following: original papers or reviews about ORM published by italian authors or regarding experiences located in Italy. Exclusion criteria were: articles written in languages other than english or italian, conference papers and chapter books. We identified potentially eligible papers from abstracts and titles; full-text of relevant studies were then assessed for inclusion and their reference lists were searched for additional studies.

\subsection{Results}

We found 12 articles meeting inclusion criteria: nine from Medline and three from hand-search. We classified the papers in five groups (Table 1), depending on their contents: studies describing practical experiences regarding ORM reorganization in clinical hospitals $(n=2)$, articles about operating room processes analysis $(n=3)$, simulations of management models conducted on real data taken from hospital archives $(n=5)$, surgical waiting list management $(n=1)$ and literature reviews on operational research aimed to surgery planning and scheduling $(n=1)$. Italian regions involved in projects or simulations on real data are: Emilia-Romagna (Forlì, Ferrara, Parma), Liguria (Genoa), Tuscany (Empoli), and Lazio (Rome). Year of publication ranged from 2007 ( $n=1$ ) to 2018 $(n=1)$, with at least one article published in each year.

We took in exam the articles in line with the classified subgroups mentioned above.

\subsubsection{ORM reorganization experiences}

Agnoletti et al. [20]describe a bottom-up project aimed at optimizing existing resources in a context of economic hardship at the Morgagni-Pierantoni Hospital in Forlì (EmiliaRomagna). The project was carried on by a multidisciplinary working group composed of anesthesiologists, surgeons, nurses and engineers. It was aimed to realize a system for data recording (DRS) and a system for data elaboration (called operating room management system or ORMS) able to track each phase of patients' flow within the OR. A bar code reading system was identified as the simplest and fastest way to gather data. The different surgical path timeframes were tracked by anesthesiological nurses. The second step was to develop ORMS to process data to simple and understandable 
TABLE 1: Articles' details listed by year of publication. (Author's own work)

\begin{tabular}{|c|c|c|c|c|c|}
\hline Authors & $\begin{array}{c}\text { Year of } \\
\text { publication }\end{array}$ & $\begin{array}{c}\text { Intervention } \\
\text { Location }\end{array}$ & $\begin{array}{c}\text { Intervention } \\
\text { Hospital }\end{array}$ & Language & Typology \\
\hline Testi et al.[15] & 2007 & Genoa & $\mathrm{n} / \mathrm{a}$ & English & $\begin{array}{l}\text { ORM model } \\
\text { simulation }\end{array}$ \\
\hline Testi et al.[16] & 2008 & Genoa & San Martino & English & $\begin{array}{l}\text { Surgical waiting } \\
\text { lists }\end{array}$ \\
\hline Testi et al.[17] & 2009 & Genoa & San Martino & English & $\begin{array}{l}\text { ORM model } \\
\text { simulation }\end{array}$ \\
\hline Guerriero et al.[18] & 2010 & $\mathrm{n} / \mathrm{a}$ & $\mathrm{n} / \mathrm{a}$ & English & Literature review \\
\hline Agnetis et al.[19] & 2012 & Empoli & $\begin{array}{c}\text { San } \\
\text { Giuseppe }\end{array}$ & English & $\begin{array}{l}\text { ORM model } \\
\text { simulation }\end{array}$ \\
\hline Agnoletti et al.[20] & 2013 & Forlì & $\begin{array}{l}\text { Morgagni- } \\
\text { Pierantoni }\end{array}$ & English & $\begin{array}{c}\text { ORM } \\
\text { reorganization }\end{array}$ \\
\hline Agnetis et al.[21] & 2014 & Empoli & $\begin{array}{c}\text { San } \\
\text { Giuseppe }\end{array}$ & English & $\begin{array}{l}\text { ORM model } \\
\text { simulation }\end{array}$ \\
\hline Buccioli et al.[22] & 2014 & Forlì & $\begin{array}{l}\text { Morgagni -- } \\
\text { Pierantoni }\end{array}$ & English & Process analysis \\
\hline Barbagallo et al.[23] & 2015 & Rome & $\begin{array}{l}\text { Bambin } \\
\text { Gesù }\end{array}$ & English & $\begin{array}{l}\text { ORM model } \\
\text { simulation }\end{array}$ \\
\hline Scagliarini et al.[24] & 2016 & Ferrara & Sant'Anna & English & Process analysis \\
\hline Mitello et al.[25] & 2017 & Rome & $\begin{array}{c}\text { San Camillo } \\
\text { Forlanini }\end{array}$ & Italian & Process analysis \\
\hline Ferrari et al.[26] & 2018 & Parma & $\begin{array}{l}\text { University } \\
\text { Hospital }\end{array}$ & English & $\begin{array}{l}\text { ORM } \\
\text { reorganization }\end{array}$ \\
\hline
\end{tabular}

$\mathrm{n} / \mathrm{a}=$ not available

performance tachometers and tables. ORMS was layered into different data output profiles and every user had access to data depending on his/her professional needs. Data output profiles were: manager, surgeon and anesthesiologists. The authors show how the implementation of this project improved the efficiency of the operating room process and improved patient safety. The number of unscheduled procedures performed was reduced while maintaining the same percentage of surgical procedures. The number of overtime events decreased as well. One of the major strengths of the project was determined by its low cost and its financial and process sustainability.

The paper of Ferrari et al. [26] reports a project of deep reorganization in the surgery network at the University Hospital of Parma (Emilia-Romagna). Before reorganization, the whole surgical process was analyzed and split up into steps, from registration on the waiting list to hospital discharge. A multiprofessional team was created to coordinate and plan the whole surgical pathway. The team (called Surgical Activity Management Board) was composed by a Surgical Activity Manager (a surgeon with management and planning skills), an anesthesiologist, an operating room head nurse, a bed management nurse and a hospital medical manager. Furthermore, to increase efficiency and OR 
utilization rate, the time allocated for elective surgery was extended (operating room verticalization), with the additional benefit of ensuring OR availability for emergency cases or high specialized surgery. Additional changes were implemented, such as the merging of surgical units and the strengthening of IT services to support the OR scheduling. This reorganization process was developed according to regional law[27], which provide parameters and guidelines for the management of surgical activity and surgical waiting lists. All the implemented changes increased the number of surgical interventions by more than 20 percent and allowed a better OR utilization.

The above presented studies are characterized by the involvement of all ORM interested stakeholders, in common: managers, surgeons, anesthesiologists and nurses. The project of Ferrari [26] shows two important aspects, as it was specifically designed taking into consideration the national and regional regulations about surgical waiting list and because it explicitly introduces a new professional profile which is just partially required by regional indications.

\subsubsection{OR processes analysis}

The article of Buccioli et al. [22] present a research project focused on costs analysis conducted at Forlì Hospital (Emilia-Romagna). They describe the development of a Cost Accounting Model through IT implementation aimed to calculate the overall cost of each surgical procedure performed into the ORB, relying on an interdisciplinary steering committee (anesthesiologists, physicians, nurses, engineers). Single surgical procedures were chosen as cost objects. All activities of the surgical path have been mapped in a flowchart where the whole process was broken down into its single path steps. Cost calculation analysis was used to process data to simple and understandable performance pie charts and tables that have been provided to hospital managers as a support for decision-making activities. After receiving OR reports, the OR managing board decides whether and/or how to implement changes in order to improve efficiency of the surgical process. Despite the project was not fully implemented, the authors claim that their prototype shows interesting cost accounting results, suggesting the possibility for costs reduction and efficiency augmentation for the services involved.

Scagliarini et al. [24]perform a retrospective analysis about OR turnaround time at the Sant'Anna University Hospital in Ferrara (Emilia-Romagna). The authors calculated, through a statistical tool, the OR turnaround time over one year which is an important efficiency indicator due to expensive OR cost for minute. By adopting specific control charts, they were able, to track the accurate performance trend of the OR turnaround time and 
consequently they found all the anomalies which differed from average turnaround time. The authors conclude that statistical quality control is a good way to monitor performance because it allows to detect process improvement or deterioration and it can support hospital managers in their activity.

Mitello et al. [25]describe an organizational analysis performed at the S. Camillo Forlanini Hospital in Rome (Lazio) to evaluate OR efficiency in two different surgical blocks. The observation, carried out through process management approach, focuses on three targets: product, patient and safety. "Product" is related to the logistic management of material supplies and storage needed within the surgical process. "Patient" refers to the patients' flow between ORs and clinical wards. "Safety" concerns the surgical perioperative procedures such as operative field preparation and patient positioning. The surgical intervention and its duration were not considered. For each element, several indicators were used: type of activity, involvement of relevant stakeholders, duration and satisfaction index among patients and professionals. Results show significant differences between the two surgical blocks so the authors conclude that a strategic lean management should be adopted in order to implement processes which increase quality, efficiency and reduce waste reduction.

The first paper of the above described studies [22] concerns OR cost analysis and for this reason it is different from the other three papers which are not directly related to this topic. Although they take into consideration different key performance indicators (KPIs), the other two studies show the importance of carefully monitoring all OR processes in order to know their status in real time and to get instant feedbacks on critical areas. Scagliarini et al. [24] analyzed only OR turnaround time. Mitello et al. [25] operated an organizational analysis only on two ORBs differently to the other two projects which 1analyzed the global OR activity of the hospital.

\subsubsection{Literary review}

Guerriero et al. [18] provide a literature review of the main scientific contributions that present mathematical models (deterministic and stochastic), simulation techniques and solution approaches to address problems arising in the ORB management. The authors conducted a literature review on articles despite their geographical origin. They argue that ORM approaches can be useful in order to increase patient throughput, improve satisfaction of patients, surgeons and OR staff, maximize the utilization of ORB resources, reduce surgery cancellations, reduce time loss due to late starts and changeover. It is 
not known, however, if these solutions have ever been applied, to what degree, and with which results, in the Italian context.

\subsubsection{Simulations of management models}

Testi et al. [15] describe a three-phase hierarchical approach that consists in planning respectively: the number of surgical sessions assigned to every operative unit, the master surgical schedule (MSS) and the surgical case assignment (SCA). After planning, a simulation with real data from a public hospital in Genoa (Liguria) was conducted. The results show, by application of this model, an increase of OR utilization with a greater number of surgical interventions performed together with a reduction of postponed or cancelled surgical sessions. In addiction this approach implies a reorganization of the wards, where one section remains closed during the weekends because it's reserved for short stay patients while the other is planned for long stay patients.

Testi and Tanfani [17] explain a linear programming model for OR scheduling which aims to address MSS and SCA problems with a careful programming of surgical cases based on patients' clinical priority. The model has been simulated on a real scenario in the General Surgery Department of San Martino University Hospital of Genoa (Liguria). It it has proven a good reproducibility in a real scenario and positive social implications because its primary goal is preventing patients' stress due to late call for surgery, rather than increasing the number of surgical interventions. In fact, it can achieve a reduction of the socio-economic costs related to illness, alongside with an increase in efficiency and a better accessibility to surgical interventions.

One research group published two articles which belong to this article category. In the first [19] they carry out several simulations during one year period to compare for different MSS models, based on real data of San Giuseppe Hospital in Empoli (Tuscany). These policies differ for the flexibility degree of the MSS: static model with a fixed schedule, dynamic model with little but frequent changes allowed and totally flexible model with continuous variations in its pattern. The analyzed indicators are the following, expressed as average weekly values: number of surgical interventions performed, interventions delays related to the patient priority class and OR underutilization rate. Results show an improvement of all these indicators through utilization of dynamic policy. Therefore, the authors state that this approach is able to increase the efficiency of surgical departments and the respect of the waiting lists without worsening the organizational workload for the operators. In the second paper [21] they show a heuristic decomposition approach, which consists in considering separately the assignment of 
different surgical specialties to the available sessions (MSS) and the selection of elective cases of that surgery pathway (SCA). Computational experiments were executed to compare this model with an integrated mathematical approach. Tests were conducted on real data of San Giuseppe Hospital in Empoli (Tuscany). The results prove that computational times required to elaborate, OR scheduling are significantly shorter for decomposition approach than integrated model. At the same time the solutions developed were near to the optimum. For this reason the authors propose the developed model as a useful decisional tool to support OR managers work.

The study of Barbagallo et al. [23] has been conducted by a multidisciplinary team at the Bambino Gesù Children's Hospital in Rome (Lazio). The research process consists in three major sequential steps: definition of the pathway as a standardized path representing the operating process (from "patient inserted onto the waiting list" to "patient operated upon"), a detailed parameterization of all resources, tasks, and times, related to the processes, and an optimization model for developing OR schedules. The developed model has been applied retrospectively to analyze OR planning of the hospital within a 5-week time period. Results show an increase on patient scheduling of 30 percent. Additional benefits derive from a better utilization of the OR with increased efficiency and increased operating room utilization rate (up to 20 percent) while the time of registration into the waiting list is longer (for patient variables and surgical variables).

Among the articles mentioned above, two papers [15, 21] suggest to plan OR processes by separately considering MSS and SCA. This model, such as the dynamic strategy proposed by Agnetis et al. [19], allows a better slot allocation based on organizational hospital needs and allows a greater adherence to surgical waiting list time, depending on patients' clinical priority. The paper of Testi et al. [17] analyzes more in detail the socio economic benefits of a correct patient scheduling based on its clinical status.

Finally, all authors agree that a global approach, including bed management and the pre-hospitalization phase, is needed to increase efficiency of the models they described.

\subsubsection{Surgical waiting lists management}

Testi et al. [16] discuss a new system of classification of the patient's priority for surgical intervention, compared to the priority system adopted by Italian National Health Service based on urgency only. This model consists in a prioritization scoring algorithm which clearly represents the clinical status of patients. It considers both, urgency and priority, utilizing a special measure: NAWD (need adjusted waiting day). A simulation on real data 
of surgery waiting lists of General and Endocrine Surgery of the San Martino University Hospital in Genoa (Liguria) was performed. Efficiency as well as equity increase with the algorithm, as a greater number of patients is assisted and more patients are admitted in hospital due to their clinical needs.

The model here proposed has the purpose of providing a tool for elective surgical waiting list management, with focus to three main points: horizontal equity (patients allocated in the same priority class should be admitted at the same time), vertical equity (patients with greater clinical needs should be treated in a shorter time) and efficiency (number of surgical interventions performed). Both are aimed to ensure a proper waiting list management related to priority and urgency of care.

\subsection{Discussion}

We have carried out a literary review about the state of the art of ORM in Italy in order to observe its development and application in relation to the financial crisis occurred during 2008. No previous article concerning ORM in Italy was published before and therefore our review is the first to analyze this topic.

The results show that, during the time period analyzed, the papers have been released over the years with a positive trend and this represents a sign of growing interest for the ORM. The financial crisis probably has promoted research in order to find new management models suitable to ensure increasing productivity rates in compliance with healthcare quality preservation.

Furthermore, as showed in the subgroups classification, the papers' contents are quite heterogeneous.

We have found two articles about ORM reorganization projects. They describe practical experiences in order to improve the global OR process. The projects were supported by collaboration between surgeons, anesthetists, medical and general direction doctors and nurses. In fact in Italy, in addiction to clinical and management engineers who are obviously expert about ORM, the number of the doctors involved in the management is growing [28]. This aspect certainly facilitates the application of these models in the clinical environment and confirms the interest for the topic not only by the managers but also by the physicians. Papers regarding process analysis show how the OR activities measures are of paramount importance as first step to reshape OR pathway.

In the other two groups, ORM model simulation and surgical waiting lists management, the authors explain theories aimed to schedule surgical interventions in accordance with patient priority and organizational needs. The global effect of these 
actions is to reduce inequities in access to surgical services that are still relevant despite the universal nature of the Italian National Health Service [29]. Finally the review analyzes the ORM studies reported in the literature and their impact on the hospital staff and efficiency rates.

Therefore we can state that all the articles included in our study describe a common intention of the italian scientific community to develop new ORM methods. The strategies proposed deal with the stringent measures provided in the regional and national regulations regarding healthcare sector. These latter require, in addition to the public sector cuts operated by the italian government, a ORM reorganization in order to improve efficiency and productivity by the optimization of the global OR functionality. A clear example of this is the regional regulation [27] cited in one paper of our study[26]. It provides two key points: the respect of the surgical waiting list times and the monitoring of the waiting list state by the region. Therefore the hospital managers have to apply a correct strategy for the OR blocks to implement these dispositions and this appears to be a difficult task due to the limited resources available.

The methods explained in the articles of our study have a good reproducibility level because they have been simulated or tested in contexts with features common to most of the hospitals. Moreover, the cost to adopt these strategies is very low because their goal is to improve the productivity without an increase in the number of professionals or in the amount of resources.

For all these reasons the strategies explained in our study can be applied to other similar contexts because OR represent one of the most important items of expenditure.

\section{Conclusion}

Our review shows a growing interest in the italian context for the ORM topic. The financial crisis occurred in 2008 has certainly boosted the research regarding ORM. In fact austerity measures adopted by italian government produced cuts in the public sector, healthcare included. Consequently hospital managers had to govern OR process with reduced resources.

The methods explained by the articles analyzed in this review present a good reproducibility level and low cost for their implementation in a clinical context. For these reasons these strategies can be shifted and applied in other similar situations in which ORM plays a crucial role. 
This study presents a limit. We analyzed only experiences published in scientific literature therefore we cannot exclude that some Italian hospitals or research groups have developed ORM reorganization projects.

Nevertheless, in light of the persisting financial crisis and the austerity measures still adopted by several governments, the interest for the ORM topic will probably increase not only in Italy but especially in other countries in which today it is less known.

\section{Acknowledgment}

$A R, P P$ and $M B$ conceived and designed the study. AR and AU carried out the review, acquired, analyzed, and interpreted the data. PP checked data extractions. AR and PP drafted the manuscript, which was critically revised for important intellectual content by all authors. MB supervised the study.

\section{Funding}

This research did not receive any specific grant from funding agencies in the public, commercial, or not-for-profit sectors.

\section{References}

[1] Long W., Li N., Wang H., and Cheng S. (2012). Impact of US financial crisis on different countries: Based on the method of functional analysis of variance. Procedia Comput. Sci., vol. 9, pp. 1292--1298.

[2] Diacon P. E.,. Donici G. A, and Maha L. G. (2013). From the Global Crisis to the National Crises: The Case of the European Union Countries. Procedia Econ. Financ., vol. 6, no. 13 , pp. $41-47$.

[3] Monastiriotis V., Hardiman H., Regan A.,et al. (2013). Austerity measures in crisis countries --- results and impact on mid-term development. Intereconomics, vol. 48 , no. 1, pp. 4--32.

[4] Karanikolos M., Heino P., McKee M., et al. (2016). Effects of the global financial crisis on health in high-income OECD countries: A narrative review. Int. J. Heal. Serv., vol. 46, no. 2, pp. 208--240.

[5] Denton B., Viapiano J., and Vogl A. (2007). Optimization of surgery sequencing and scheduling decisions under uncertainty. Health Care Manag. Sci., vol. 10, no. 1, pp. $13--24$. 
[6] Marjamaa R., Vakkuri A., and Kirvelä O. (2008). Operating room management: Why, how and by whom?. Acta Anaesthesiol. Scand., vol. 52, no. 5, pp. 596--600.

[7] Aringhieri R., Tànfani E., and Testi A. (2013). Operations research for health care delivery. Comput. Oper. Res., vol. 40, no. 9, pp. 2165--2166.

[8] Hans E. W.and Vanberkel P. T. (2012). Chapter 5 Operating Theatre Planning and Scheduling, Handbook of Healthcare System Scheduling. Handb.131--154. Springer.

[9] Romeijn H. E.and Zenios S. A. (2009). Introduction to the Special Issue on Operations Research in Health Care. Oper. Res., vol. 56, no. 6, pp. 1333--1334.

[10] Ricciardi W., Specchia M. L., Ferrè F., et al. (2012). The financial crisis in Italy: Implications for the healthcare sector. Health Policy (New. York)., vol. 106, no. 1, pp. 10--16.

[11] Government of the Italian Republic, Legge 161/2014 - Articolo 14 - Disposizioni in materia di orario di lavoro del personale delle aree dirigenziali e del ruolo sanitario del Servizio sanitario nazionale. Gazzetta Ufficiale della Repubblica Italiana, 2014.

[12] Italy Health Ministry, Piano nazionale di governo delle liste di attesa per il triennio 2010-2012, (PNGLA 2010-2012).

[13] Cardoen B., Demeulemeester E., and Beliën J. (2010). Operating room planning and scheduling: A literature review. Eur. J. Oper. Res., vol. 201, no. 3, pp. 921--932.

[14] Wachtel R. E. and Dexter F. (2013). Difficulties and challenges associated with literature searches in operating room management, complete with recommendations. Anesth. Analg., vol. 117, no. 6, pp. 1460--1479.

[15] Testi A., Tanfani E., and Torre G. (2007). A three-phase approach for operating theatre schedules. Health Care Manag. Sci., vol. 10, no. 2, pp. 163--172.

[16] Testi A., Torre G. C., Tanfani E., et al. (2008). Prioritizing surgical waiting lists. J. Eval. Clin. Pract., vol. 14, no. 1, pp. 59--64.

[17] Testi A. and Tànfani E. (2009). Tactical and operational decisions for operating room planning: Efficiency and welfare implications. Health Care Manag. Sci., vol. 12, no. 4, pp. 363--373.

[18] Guerriero F.and Guido R. (2011). Operational research in the management of the operating theatre: A survey. Health Care Manag. Sci., vol. 14, no. 1, pp. 89--114.

[19] Agnetis A., Coppi A., Corsini M., et al. (2012). Long term evaluation of operating theater planning policies. Oper. Res. Heal. Care, vol. 1, no. 4, pp. 95--104.

[20] Agnoletti V., Buccioli M., Padovani E., et al. (2013). Operating room data management: Improving efficiency and safety in a surgical block. BMC Surg., vol. 13, no. 7, pp. 1--11. 
[21] Agnetis A., Coppi A., Corsini M., et al. (2014). A decomposition approach for the combined master surgical schedule and surgical case assignment problems. Health Care Manag. Sci., vol. 17, no. 1, pp. 49--59.

[22] Buccioli M., Agnoletti V., Padovani E., et al. (2014). eHCM: Resources Reduction \& Demand Increase, cover the gap by a managerial approach powered by an IT solutions. Stud. Health Technol. Inform., vol. 205, pp. 945--9.

[23] Barbagallo S., Corradi L., de Goyet J.D.V., et al. (2015). Optimization and planning of operating theatre activities: An original definition of pathways and process modeling. BMC Med. Inform. Decis. Mak., vol. 15, no. 1, pp. 1-16.

[24] Scagliarini M., Apreda M.,Wienand U. (2016). Monitoring operating room turnaround time: a retrospective analysis. Int. J. Health Care Qual. Assur., vol. 29, no. 3, pp. 351--359.

[25] Mitello L., D'Alba F., Milito F., et al. (2017). Improving operating room efficiency: an observational and multidimensional approach in the San Camillo-Forlanini Hospital, Rome. Prof. Inferm., vol. 70, no. 2, pp. 66--75.

[26] Ferrari F.A., Manotti P, Del Rio P, et al. (2018). Project design for surgical department reorganization at hospital-university of Parma. Acta Biomed, vol. 89, no. 2, pp. 165-172.

[27] Region Emilia-Romagna, DGR 272/2017: Riduzione delle liste di attesa per i ricoveri chirurgici programmati nella Regione Emilia-Romagna. 2017.

[28] Lega F.and Sartirana M. (2016). Making doctors manage... but how? Recent developments in the Italian NHS. BMC Health Serv. Res., vol. 16, no. 2, pp. 65-72.

[29] Glorioso V. and Subramanian S. V. (2014). Equity in access to health care services in Italy. Health Serv. Res., vol. 49, no. 3, pp. 950--970. 